\title{
Transcultural Poetics: Dissolving Borders in the Poetry of Li-Young Lee
}

\author{
Dr. Hend Hamed Ezzeldin
}

Ain Shams University, Egypt

\begin{abstract}
:
In a world characterized by a loss of direction, an absence of hope, and a disbelief in spirituality, a world that disrespects differences, obliterates human relations, and undermines emotions, man tends to lose faith in humanity. Amidst this debris of human fragmentation and disconnectedness, Li-Young Lee ventures to reach the whole world by transcending time and space, appealing to the metaphysical, and excluding the cultural. This research paper aims to highlight Li-Young Lee's endeavors at creating tight bonds between himself and the rest of the world by unifying the dichotomies of the self and the other, interlacing a web of mutuality to embrace the entire universe. Lee calls into question the separation between beginning and end, birth and death, past and future, man and woman, and body and mind attempting to create a universal dialogue reflecting transcultural hybridity. To attain his goal, Lee depends on his memories to write poetry that is deeply personal but is universal in its appeal. Borders dissolve and language opens up to become the go-between the self and the other, giving meaning to what is invisible and evanescent.
\end{abstract}

Keywords: Transculturalism - Ethnic American Poetry - Li-Young Lee - Universalism

\section{Introduction}

Amidst wars, destruction, and bloodshed, man faces the problem of coming to terms with a world that seems to lack real spiritual significance, a world often visualized as a wasteland. The accelerated rate of killings, environmental disasters, and unaccounted for racism make the world a place of purposelessness, alienation, and bleakness. That sense of loss is usually not only outer, as it were, but also inner, producing an 'objective' world that lacks meaning or intention and a fragmented 'subjective' world. It is a challenge to any artist, thus, to deal with such loss of unity, order and belief that seems to characterize this world. In such chaos and fragmentation, human beings suffer from loss of moral and spiritual compass and "chronic absence of resources with which they could build a truly solid and lasting identity, anchor it and stop it from drifting" (Bauman 26). The rise "of relativism and skepticism to the level of a guiding doctrine has not only turned the world into a labyrinth of endless questions and humans into automated passive subjects, but it has also deprived humanity from spiritual peace, social stability, and hopes for a better future" (ElHayawi 176). Li-Young Lee exerts strenuous efforts to place himself in this world, being always placeless and diasporic. Looking beyond this world, not at it, he attempts to underscore transcultural encounters, engaging himself in universal dialogue.

\section{Transculturalism: An Overview}

In the world of today, we can no longer categorize individuals according to their origins since the idea of origin itself has become very much destabilized due to many factors including colonization, wars, immigration, diaspora and others. In his book L'impurite, Guy Scarpetta maintains that 'impurity is the order of the day. The 'we' and 'you', include also the 'he' and the 'she' of all linguistic groups, of all nationalities, of all the sexes. We are of all the cultures. Each person is a mosaic" (qtd in Cuccioletta 3). Scarpetta here implies the view that culture is an evolutionary process and that one usually recognizes oneself in the other.

The term 'transculturalism' is sometimes used alternately with the term cosmopolitanism. A cosmopolitan is defined as "someone who thinks that the world is, so to speak, our shared hometown, reproducing something very like the selfconscious oxymoron of the global village" (Appiah 217). Transculturalism was originally coined in 1940 by the historian Fernando Oritz in his book Cuban Counterpoint: Tobacco and Sugar. Oritz defines transculturalism as a: 
Synthesis of two phases occurring simultaneously, one being a de-culturization of the past with a metissage with the present. This new reinventing of the new common culture is therefore based on the meeting and the intermingling of the different peoples and cultures. In other words, one's identity is not strictly one dimensional (the self) but is now defined and more importantly recognized in rapport with the other. In other words, one's identity is not singular but multiple. (qtd. in Cuccioletta 8)

Hence, transculturalism proposes a deconstruction of cultural boundaries. We no longer speak of "integration of a minority culture into the mainstream, but of an interweaving of all cultural identities present in a nation-state" (Grosu 108). This idea calls for encompassing, respecting, and embracing the cultural specificities of different races and ethnicities, leading to the recognition of the self in the other.

In Germany, a group of scholars including Frank Schulze-Engler, Sabrina Brancato, and others have introduced the field of transcultural English Studies. Schulze-Engler maintains that transcultural English studies:

Stands for a genuinely transnational and transcultural perspective that is capable of encompassing both the literary practice of writers who can no longer be related to one particular 'national literary space' and the complex articulations that link individual works of literature not only to local or regional modernities with their specific social, linguistic, and cultural constellations, but also to the world-wide field of English language, literatures and specific forms of communicative interaction and political conflict engendered by it. (qtd in Dagnino 2)

Thus, transcultural literary works "engage with and express the influential nature of cultures overcoming the different dichotomies between North and South, the West and the Rest, the colonizer and the colonized, the dominator and the dominated, the native and the (im)migrant, the national and the ethnic" (Dagnino 3). The foundation of transcultural literature springs from its globalizing or universalizing forces which tend to restructure our cultural, economic, and social landscapes as in the "literary discourse related to mobility at large, including its migrant, diasporic, postcolonial, and transnational variants" (Dagnino 4). It is not by coincidence, then, that immigrant literature has recently been seen in a transcultural light:

Migrant literature considers, and urges readers to consider, people, places, histories, languages, and especially poetics ... dynamically, in continuous relation to each other, rather than as mutually exclusive absolutes ... Attention is focused on the recognition ... of porous borders, on the construction of zigzagging trajectories, and on the reconsideration of the complexity of cultural systems traditionally codified as univocal and contaminated ... Yet, what makes migrant writing specific ... are its contemporary trans-cultural ... aspects ... and its consequent resistance to being exclusively appropriated by traditional national canons. (Di Maio 1-2)

Talking particularly about the "New Literatures in English", Schulze Engler claims that "the idea of 'locating' culture and literature exclusively in the context of ethnicities or nations is rapidly losing plausibility throughout an 'English-speaking World' that has long since been multi-rather than monolingual" (qtd in Dagnino 4). Thus, the notion of making the strange stranger and the foreign more foreign that is taking place in the world of today, could no longer be tolerated. The division of the world "between the West and the rest; between locals and moderns, between a bloodless ethic of profit and a bloody ethic of identity; between 'us' and 'them'" (Appiah xxi) is not applicable anymore. In our globalized way of living, "culture should be perceived as a universal contract negotiated through a comprehensive dialogic agenda that not only accepts the otherness of the other but also allows human beings to dwell in-between cultures, unshackled by the bonds of belonging, yet bound up with an obligation to create a better future" (ElHayawi 178).

\section{Li-Young Lee}

Li-Young Lee (1957 - ) was born in Jakarta, Indonesia to Chinese parents. His first five years were spent in exile throughout Hong Kong, Macau, and Japan until his father was able to settle in the United States. Critics such as Wenying Xu underscore that Lee's condition of exile has proved to be immensely productive of emotional intensity and imagination. His poetics, Xu adds, "derive largely from his ontological condition as an exile, driven by the desire to transcend time and space by appealing to the metaphysical, to the exclusion of the cultural and material" (129). While educing his experience as an ethnic 'other', Lee's poems resist social inscriptions, racial definitions, and ethnic stereotypes. Being a 'winged' seed, LiYoung Lee does not identify himself with a specific place or a specific culture. His Chinese memories seldom link him with his homeland or awake any kind of nostalgia for Asia as he spent a very long time of his life in exile. This sense of belonging to a particular land is completely lost for Lee who always describes himself as a 'guest' on earth. The first common denominator that gathers all humanity under its umbrella is this sense of loss on planet earth and the incessant search for 
a place that could encompass and tolerate all differences and variances. For Lee, this place is the whole cosmos, to which he is always associated. The whole human race belongs to this universe, and thence, all people are similar in that they share many common realities. In his poetry, Lee expresses feelings of alterity and inferiority, being an Asian American trying to assimilate in a foreign culture that does not respect differences. To pave the way for his transcultural poetics, Lee proposes a universal self that experiences similar knowledge, trajectories, and even destinies. In his interview with Tod Marshall, Lee states:

I am perfectly convinced that that's what I am, the universe. I can't live it. Why? So the poetry comes out of that. The poetry comes out of a need to somehow - in language - connect with universe mind, and somehow when I read poetry - and maybe all poetry is quest, a poetry of longing - when I read poetry, I feel I'm in the presence of universe mind;...SO that's why I read poetry, and that's why I write it, to hear that voice, which is the voice of the universe. (130)

Lee believes that the role of poetry and poets is of immense importance in the society to the extent that he puts poetry and religion on equal levels. "It [Poetry] is the practice of the sacred ...", Lee explicates in an interview with Tod Marshall (139). Poetry is a spiritual activity that starts individually and then moves outward to contain the whole world. In the same interview, Lee adds:

We're in service to poetry. Poetry is something greater than we are. You see, the whole universe is a poem! It has no rational meaning. It has no reason for being. Yet it is. All of the laws, all of the universes' laws, are poetic laws. None of them are logical; all of them defy understanding. All of them are great. Everything we say about a great poem is true about the universe. (145)

Poetry becomes Lee's means to reach universalism and underpin transcultural ethos.

\section{Transcultural Encounters in the Poetry of Li-Young Lee:}

\section{Memory}

Lee is contingent on his personal memory as a way of identity-formation. This process of recovering personal heritage reveals both the confusion of the immigrant condition and the underlying universality that emerges from this confusion. In his poem 'The Cleaving', for example, the Chinese immigrant self is portrayed as being chopped and cut into pieces like the meat at the butcher's. For the poetic persona, the Chinese butcher does not only bring back images of ancestors back in China and of the painful process of immigration, but also induces the fear of cutting and fragmentation, wounds and bleeding in socio-cultural and personal terms. Images of migration to the US gradually metamorphose into images of the chopping of the duck, and finally evoke a metaphorical halving of the 'I. In his book Cities, Borders and Spaces in Intercultural American Literature and Film, Jesus Benito explains:

Lee's intervention ... underlines the immigrant's assimilation of the wound, the self's metaphorically fingering the open wound and sucking up its blood. The bridging of the gap between self and other, immigrant and local, is dramatized in the poem not so much through the jump into the other's territory as through the permanence in the painful middle ground. Despite its emphasis on cleaving and cutting, the poem veers toward communion and restoration; rather than hoping for unattainable healing, it manages to extract sustenance from the wound. (104)

The sense of 'placelessness', of being "lost in America" (Lee Seed 76) - of being an outsider, a shadow, an inhabitant of a "city I call home, in which I am a guest" (Lee Seed 51) pervades Lee's poetry. The feeling of displacement and disconnectedness is particularly disturbing for the poet, since he cannot even re-create the Chinese homeland, which he never really knew or felt. Lee "represents the figure of the dweller of the nowhere, the inhabitant of the places of nonexistence who struggles to make 'placelessness' his home" (Benito 105).

This feeling of fragmentation and disintegration becomes deeper due to Lee's ideologies and convictions. Lee rejects the common definition of the word 'culture' and sees it as a low version of oneself. In The Winged Seed, Lee's poetic alter ego describes himself as a ghost who "got lost and now is trapped between two worlds" (120). Rather than spanning two cultures, Lee decides to occupy the abyss, the gap separating them, as represented in 'The Cleaving'. In his interview with Tod Marshall, Lee explicates: 
I have no dialogue with cultural existence. Culture made that up - Asian-American, AfricanAmerican, whatever. I have no interest in that. I have an interest in the spiritual lineage to poetry through Eliot, Donne, Lorca, Tu Fu, Neruda, David and the Psalmist ... Somehow an artist has to discover a dialogue that is so essential to his being, to his self, that is no longer cultural ... but a dialogue with his truest self. His most naked spirit. (132)

For him, cultural identities are works of the rational mind, and true poetry works against it. Thus, Lee proposes an escape from culture as particular location, culture "built on sand" (Lee 'Marshall' 133) that looks solid but is misleading. Lee never referred to himself as an Asian American writer. He believes that reading Asian American Literature through the lens of ethnicity only empowers a certain population and potentially 'ghettoizes' the writer and treats him/her as a subaltern figure rather than a talented individual. Instead, the poet appeals for a 'nobodyhood' that defies material and cultural political emplacement and chooses to rebuild the moment of the cutting of the self from its sheltered place. Paradoxical as it seems, this 'nobodyhood' is turned into an 'everybodyhood' that strives to achieve the state of the naked self in relation to God and the universe. Presenting the fundamental vision of a space where all beings, "through splitting and connecting life and death as well as immanence and transcendence, exist immanently without divisions between transcendentality and materiality, animality and humanity, and subject and other" (Kim 29) is the aim of Lee's poetry in general. The poem ends with an image of gathering of all diverse immigrants into one common place:

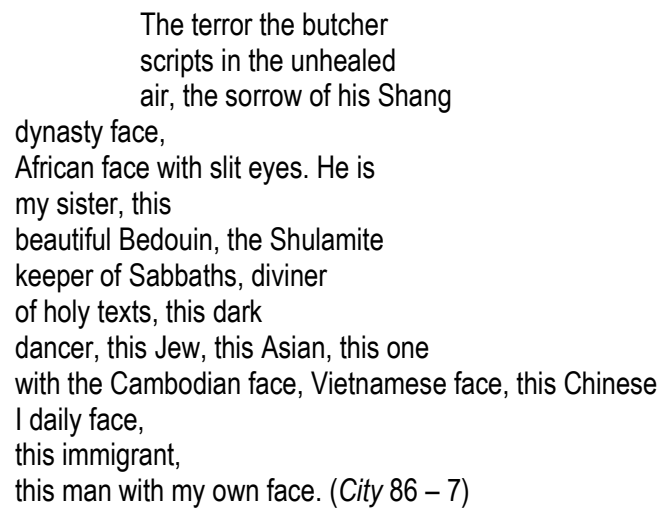

The poem's conclusion suggests a bridging, if not a destruction, of any gap that separates between different entities in the universe. This bridging of the gap between the self and the other is not confined to Asian American immigrants only but also to the Asian Diaspora, as well as the Middle East and Africa, concurrently dissolving the gap between genders ("He is my sister") and highlighting the state of 'universality' that Lee believes in. That is why when Li-Young Lee discusses his art in interviews, he often speaks of the universal self and the link between all beings even though the context of his poems, like 'The Cleaving', are focused much more on the struggles of alienation, isolation and disconnection between people and the universe around them. Lee digs deep in his memory in an endeavour to place himself in context of a more universal existence.

\section{Language}

Upon his arrival to the United States, Lee found linguistic communication a burden. In his poem 'Persimmons', Lee narrates a situation that happened to him at school when his class teacher scolded him physically and psychologically for not being able to differentiate between the two words 'persimmons' and 'precision':

In sixth grade Mrs. Walker

slapped the back of my head

and made stand in the corner

for not knowing the difference

between persimmon and precision. (Rose 17) 
The word 'persimmon' is not easily pronounced by the poet because English is not his mother tongue and because the system of the Chinese phonetics "does not include the complex syllable onset of the pr- at the beginning of the word precision as an allowable sequence" (Yao 7). In the next stanza, the persona shows his masterful knowledge of the English language by explaining the difference between these two words as well as other words such as 'fright' and 'fight' and 'wren' and 'yarn'. The narrator, then, begins to bring forth vivid images of his mother and father and their interconnectedness with the 'persimmons' which tends to be an image of love and tenderness. The poem earnestly relates various aspects of immigrant experience in America underpinning the dilemma linked to learning (or failing to learn) English pronunciation, the sense of profound alienation and otherness that "arises from a confrontation with mainstream ignorance and cultural insensitivity, and finally the anxiety over a loss of connection with the original or parental culture" (Yao 5). The narrator's varied experiences, in this poem, "reveal complications of living as an ethnically Chinese person in America: assimilation into American culture, orientalist exoticization and white mainstream appropriation of Chinese culture" (Chan). The fact that Lee, in the coming stanzas, succeeds in explaining the difference between the two words and other words too indicates that language is not an impediment for him, but the difficult thing is to emerge into a foreign society; the act that became more problematic from his teacher's scolding and racial hints. The poem "achieves a triumphal narrative of integration and synthesis wherein the poet ... enters fully into (indeed, contributes to the formation of) multicultural American society by mastering its operative language, as evidenced by the poem itself" (Zhou 32). In his interview with Tod Marshall, Lee explains that everything in life is discourse. He says:

... It's like a big roar, a big hum. Everything is language. Trees are language; birds are language. A bird is a little cipher. A bird is a word. Beyond the word for bird, bird is a word ... A tree is a word that refers to something else. The ocean is a word; each wave is word. The whole world is language to me ... A word is a vibration; a leaf is a vibration ... Branches are words! ... I feel like it's all language. It's all conversing. Apples on the trees: I look at them and see all these words on the trees. It's all language. All of it. This table is a very bad form of language. This room is language; when you walk into this room, it's saying something. (143)

In his interview with Dianne Bilyak, additionally, Lee talks about his concept of 'word'. He states:

When I was a kid, I felt as if everything was talking to me. I would walk to school by the river, and it was as if everything knew my name; I mean I literally felt that I thought, "Oh, okay, then everything is talking, everything is in discourse, everything is in dialogue ... (607)

Lee's conviction that everything in life is conversing gives language a role of being not only a mediator between people, but also a means of communication between different parts of nature. Language, for Lee, does not only refer to what is visible, but creates the 'invisible' harmony between earthly and sublime matters. Thus, when writing about abstract notions such as language, Lee seeks connections even if he is describing alienation and disconnection. Although the poem appears to be dominated by lack of communication and misunderstanding, Lee "is always seeking to show how there is a oneness that binds everything together" (Duncan 32). The "multiplicity of meanings and materiality of persimmons and the sensibility and spirituality of the speaker's immigrant parents, challenge mainstream America's reductive view of difference" (Zhou 33). This 'oneness' or 'allness' is one of the main aims of language.

\section{Eating}

In his poem 'Always a Rose', Lee explicates: "So I was given the remedy of the rose, / made to eat you whole, / swallow your medicinal taste" (Rose 39). In one of his interviews, Lee confides that his father taught him that roses could be eaten and that the rose is a main ingredient in many Chinese dishes cooked by his mother. Ostensibly, through this autobiographical reference to eating roses in general and to eating roses as remedy in particular, Lee introduces the motif of eating which refers to the idea of opening the self to the other as well as transforming the self through otherness. Thus, eating becomes the pattern for accepting otherness into sameness for the sake of self-metamorphosing. As the poem develops, eating becomes a symbol of resisting suffering, comprehending the self and the other, as well as exploring otherness:

body, I eat you

Odorous and tender flower -

to recall my first misfortune. 


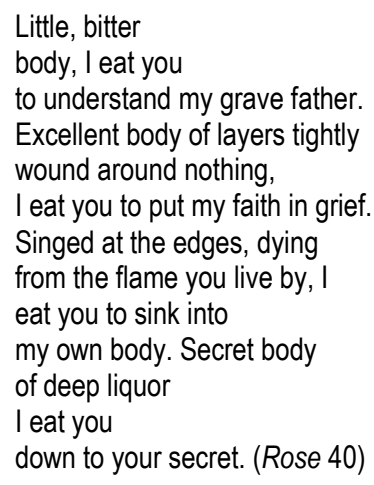

In his book The Ethics and Poetics of Alterity in Asian American Poetry, Xiaojing Zhou maintains that eating as a reaction to otherness renders the self defenceless and susceptible to the other because of the self's corporeality. Thus, "eating serves more than a cognitive function; it enacts openness to and contact with the other through what Levinas might call 'sensuous exposure' to alterity" (40). Lee's sumptuous experience with alterity prevents the lyrical 'I" from assuming mastery over the other.

In 'The Cleaving', the image of the butcher gives way to succeeding images of eating and devouring. Though eating becomes the ultimate image of death and dissolution, it also signals growth and blending of opposites. A recurrent trope in Asian and Asian American literature, eating is "a cultural activity that evokes family ties and generational continuity ... Ingestion is the physical act that mediates between self and non-self, nature essence and foreign matter, the inside and the outside" (Partridge $82-3$ ). It, thereupon, represents the split, the wall, or the dividing line. In 'The Cleaving', eating reads as the chief metaphor for the marrying of opposites, "as well as the opening of the self to whatever is new, painful, violent, and transformative" (Huang 195).

In 'The Cleaving', the speaker eats all kinds of things in life, both material and immaterial. From duck brains, he moves on to eating non-food items, such as people, their actions, their manners, and their history:

What is it in me would devour the world to utter it?

What is it in me will not let

the world be, would eat

not just fish,

but the one who killed it,

the butcher who cleaned it.

I would eat the way he

squats, the way he

reaches into the plastic tubs

and pulls out a fish, clubs it, takes it

to the sink, guts it, drops it on the weighing pan.

I would eat that thrash

and plunge of the watery body

in the water, that liquid violence

between the man's hands,

I would eat

the gutless twitching on the scales,

three pounds of dumb

nerve and pulse, I would eat it all

to utter it. (City $82-3$ )

The speaker of the poem 'devours' everything in life suggesting that to 'eat' something is to understand it and be part of it. In his book Eating Identities Reading Food in Asian American Literature, Wenying Xu maintains that "turning inward into 
our multiple and sometimes competing selves, we understand that we eat (live on) our identities, for they actualize and sustain our selves". "Identities", he presumes, "are to our social being what food is to our body. Without them, we do not exist" (168). Hence, the poem suggests Lee's endeavours at 'eating' the American identity to understand it and be part of the American community.

Later, in the sixth stanza, Lee hints at the possibility of eating 'death' itself. On the one hand, to eat death is to understand its essence and accept its existence. On the other, death could be used as a metonymy for history; the Asian American history in general and Lee's history of alienation and fragmentation. His eating of this history, therefore, could "serve as an elegy for all the Asian Americans who die after eating much bitterness. By eating their misery and deaths, he endeavours to understand and place himself within the Asian American history" (Xu 153). According to Sau-ling Cynthia Wong, big eaters in Asian American Literature are defined by "an ability to eat unpromising substances and to extract sustenance, even a sort of willed enjoyment, from them; to put it symbolically, it is the ability to cope with the constraints and persecutions Asian Americans have had to endure as immigrants and racial minorities" (25). Eating becomes a way of understanding the self and accepting the external other.

Lee, then, explains the cause of the anti-Chinese sentiments:

\author{
I would devour this race to sing it, \\ this race that according to Emerson \\ managed to preserve to a hair \\ for three or four thousand years \\ the ugliest features in the world. \\ I would eat these features, eat \\ the last three or four thousand years, every hair. \\ And I would eat Emerson, his transparent soul, his \\ soporific transcendence. (City 83).
}

The part in italics is a quotation from Emerson's journals and it is at this point that Lee overtly enters into a conversation with the American culture. The fact that the speaker agrees to eat such negative comments on the Chinese race and eat the person who uttered them himself makes him look like a hero who cuts the head of his foe off after a fight. Hence, swallowing hardship or eating 'bitter' is represented in this poem as a heroic act. The speaker turns the "seemingly useless into the useful" when he eats Emerson's racist remarks, hence "embrac[ing] the notion of the champion eater; he does not adopt white American eating habits but makes his pride in his own culture's customs his weapon" (Partridge 112). The rule of turning the useless into useful could also by applied to the act of eating Emerson himself. While eating Emerson would explicitly and viciously disassociate the speaker from Emerson and his ideas, as a 'food' substance, Emerson also becomes a nutrient for the speaker's poetic utterance. The poem suggests, therefore, that "positive change requires ... an 'embrace' and a 'covenant' between the racialized self and the racist other" (Partridge 114).

The trope of eating paves the way, thus, for two opposing actions on the part of Lee. It figures, on the one hand, for the poet's negation of his adversary, in this case racial hostility, and on the other, it "stands for the poet's eager loving absorption of all that is around in order to turn daily life into poetry" (Xu 153). That is why the protagonist switches from the idea of eating and devouring to the act of uttering: "I would eat it all / to utter it" (City 83). Poetry is the result of the poet eating the world and just as eating symbolically tears apart and brings back together, poetry, for Lee, carries within its boundaries the double meaning pervading the poem. In this regard, Benito explains that for Lee, the physical bodies of his fellow immigrants, as much as the world itself, become the source and sustenance of poetry. Eating becomes both "a signal of cultural communion with other Chinese immigrants (i.e. the larger cultural community) as well as the aggressive weapon against racism in American society and American culture" (Partridge 108). Eating is, thus, deployed in the poem as an active gesture of opening the self to what is new, afflictive, coercive, and diversified.

\title{
Death
}

Death is one of the most crucial topics that Lee's poetry discusses. In his poem 'Rain Diary' from his earliest volumes, Rose, Lee explores deeper implications of the protagonist's relationship with death as the mysterious, unknowable other. In this poem, death, like rain, arrives suddenly and unpredictably and leaves without a trace, "stirring the lyric speaker and compelling him to explore its unknowable mystery" (Zhou 42). The encounter with death, as 'other' in this poem, "challenges 
the subject's mastery over the self and the exterior world" (Zhou 42), giving him room to explore this inaccessible, ungraspable other.

However, in 'The Cleaving', it appears that Lee began his journey towards understanding the meaning of death. In the eyes of the speaker of 'The Cleaving', animals, the butcher, and the speaker are all related ontologically via death. The reason behind Lee's interest in death and dying is that it is one of the most known common denominators shared by all creatures on this earth. Death does not differentiate between Asian or American, white or black, or even human and animal. In the speaker's imagination in the poem in hand, the duck while being dissected by the executioner, imagines that the butcher retreats from his fear of his own death. Death is, thus, "a common, factual element among living beings, regardless of a being's hierarchal position in nature" (Kim 22). It is, also, according to the speaker the ultimate fixed truth in life that no one can escape from:

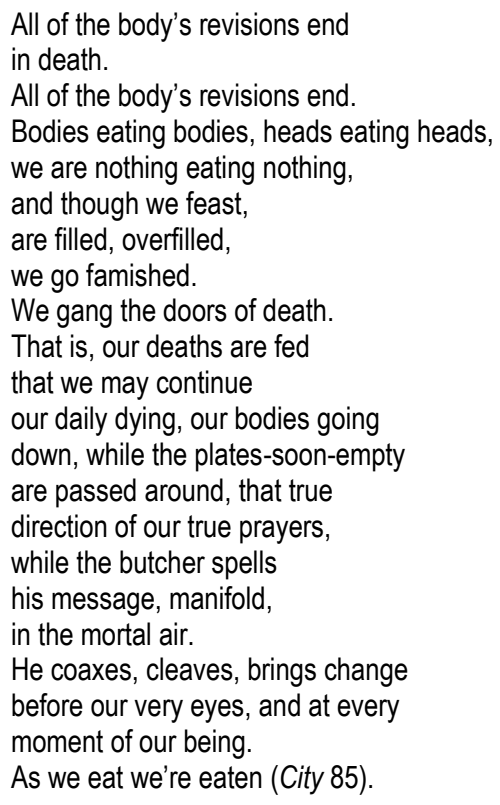

The speaker portrays death as a process that every human being must pass through. Human beings live by the dying of other creatures in the world and the opposite could be quite true as well. Having this kind of conviction made the poetic persona feel that life is about nothing since everything in life is built on the processes of eating, devouring and then dying.

In his poem 'Stations on the Sea', from Book of My Nights, Lee meditates on his dead family members. "I don't want to seem morbid," Lee states, "but it feels to me that the process of dying is actually dying into a greater presence ... we die into greater awe, greater splendour, greater terror, and greater presence" (Jordan). In 'To Hold', in addition, he begins the poem with the assumption that "we're dust" (Behind 98). Death is, thus, a recurrent motif in the poetry of Lee. Even if, at the beginning at least, it was tackled as an ungraspable idea, eventually, it was utilized as a means of transcultural hybridity in his poetry in general.

\section{Conclusion}

Despite its autobiographical and personal particularities, "the lyric I in Lee's poems is not defined or confined by autobiographical details or by his socially constructed identities" (Zhou 53). Lee's poetry tackles universal and transcultural themes masked by his personal experience. In an attempt to find a place for a self, traumatized by division and disconnectedness, the poet reconstructs reality, paving the way for a universal dialogue. Lee recreates a world, within and without, to interweave a network of relationships that would connect the people of the world. He redefines cosmic themes and relations to prove that even through multiplicity, there still is a common ground to be shared by all humans. For Lee, his immigration memories are transformed into universal interconnectedness where all distinctions and differences are 
destructed including race and gender. Language, which tends to accentuate ethnic hierarches, especially, in a multiracial society like the United States, is changed to a universal discourse. Everything in the world talks to Lee, and especially a poem. Poetry becomes a means for transcendence, spirituality, and morality. A word, a text, or a poem - all are synonymous for Lee - are the major constituents of his microcosm and macrocosm as well. He even turns eating into a cognitive, epistemological activity that helps connect the people of the world. Death, as dark and gloomy a concept as it appears to be, is seen by Lee as a transcultural destiny encountered by all people, notwithstanding any hierarchal standards. Seeking connection and creating dialogues with the whole universe is Lee's aim behind his poetic vocation.

\section{Works Cited}

[1] Appiah, Kwame Anthony. The Ethics of Identity. New Jersey: Princeton UP, 2005. Print.

[2] Bauman, Zygmunt. Postmodernity and its Discontents. Cambridge: Polity P, 1997. Print.

[3] Benito, Jesus and Anna M. Manzanas. Cities, Borders, and Spaces in Intellectual American Literature \& Film. NY: Routledge, 2011. Print.

[4] Chan, Diana K. "Struggling with Assimilation: Li-Young Lee's Persimmons". U of California. Web. 13 June 2015.

[5] Cuccioletta, Donald. "Multiculturalism or Transculturalism: Towards a Cosmopolitan Citizenship". London Journal of Canadian Studies 17. (2002): 1-11. Print.

[6] Dagnino, Arianna. "Transcultural Literature and Contemporary World Literature". CLC Web Comparative Literature and Culture 15. (2013): 1-10. Web. 16 March 2017.

[7] Di Maio, Alessandra. "Wor(I)ds in Progress: A Study of Contemporary Migrant Writings". Diss. U of Massachusetts. 2006. Web. 1 April 2017.

[8] Duncan, Paul. "Li-Young Lee: A Post-Modern Poet Travels Back to Transcendentalism". Diss.Georgetown U. 2013. Web. 3 March 2013.

[9] ElHayawi, Mayy. "Beyond 9/11: Poetics of Transcultural Agency in Contemporary EthnicAmerican Poetry". Other Modernities 9. (2011): 173-89. Web. 30 March 2017.

[10] Grosu, Lucia-Mihaela. "Multiculturalism or Transculturalism? Views on Cultural Diversity". SYNERGY 8. (2012): 104-111. Web. 30 March 2017.

[11] Huang, Guiyou. Asian American Autobiographies. NY: Greenwood, 2001. Print.

[12] Kim, Dae-Joong. "Trans-spatiality as the Horizon of the Coming Community: Ethico-Ontology and Aesthetics in Asian Immigrant Literature". Diss. U of Nebraska. 2012. Web. 20 June 2014.

[13] Jyung-Jin, James. "Li-Young Lee". Words Matter: Conversations with Asian American Writers. Ed. King Kok Cheung. Honolulu: $U$ of Hawaii P, 2000. Print.

[14] Lee, Li-Young. Rose. NY: BOA Editions Ltd, 1986. Print.

-. The City in Which I Love You. NY: BOA Editions Ltd, 1990. Print.

-. The Winged Seed: A Remembrance. Minnesota: Ruminator Book, 1995. Print.

[15] - -. Interview with Tod Marshall. "To Witness the Invisible". Kenyon Review 22. (2000): 129-47. Print.

[16] - -. Interview with Dianna Bilyak. "Interview with Li-Young Lee". The Massachusetts Review 44. (2004): 60012. Web. 20 May 2014.

-. Behind My Eyes. NY: W.W. Norton \& Company, 2008. Print.

[17] --. Interview with Marie Jordan. "An Interview with Li-Young Lee'. Association of Writers and Writing Programs AWP. May 2002. Web. 31 August 2014.

[18] Partridge, Jeffery F.L. "The Politics of Ethnic Authorship: Li-Young Lee, Emerson and Whitman at the Banquet Table". Studies in the Literary Imagination 37. (2004): 103-26. Print.

[19] Wong, Sau-ling Cynthia. Reading Asian American Literature: From Necessity to Extravagance. New Jersey: Princeton UP, 1993. Print.

[20] Xu, Wenying. Eating Identities: Reading Food in Asian American Literature. Hawaii: Hawaii UP, 2008. Web. 13 July 2014.

[21] Yao, Steven G. "The Precision of Persimmons: Hybridity, Grafting and the Case of Li-Young Lee". Literature Interpretation Theory 12. (2001): 1-23. Print.

[22] Zhou, Xiaojing. The Ethics and Poetics of Alterity in Asian American Poetry. lowa: U of lowa P, 2006. Print. 